\title{
The supramedullary cells of the teleost Coris julis (L.): a noradrenergic neuronal system
}

\author{
L. Mola, D. Sassi, and B. Cuoghi \\ Dipartimento di Biologia Animale, University of Modena and Reggio Emilia, Via Campi 213/D, I-41100 Modena, Italy
}

Accepted: 14/03/02

Keywords: teleost, supramedullary neurons, noradrenaline, autonomic nervous system, gastrin/CCK-like peptide

\section{SUMMARY}

This study, carried out on Coris julis (Labridae), is a contribution to the immunocytochemical characterization of fish supramedullary neurons. The significance of these giant cells has been debated since the beginning of the twentieth century. Our research provides the first evidence for a noradrenergic feature of this neuronal system. The possible role of supramedullary neurons as components of the autonomic nervous system is discussed. Moreover, the present results, taken together with our previous studies, surmise that this the first known case of colocalization of a neuropeptide (gastrin/CCK-like) and noradrenaline in the nervous system of teleosts.

\section{INTRODUCTION}

Many species of teleosts belonging to different orders exhibit large neurons lying on the dorsal midline surface of the spinal cord named supramedullary neurons or supramedullary cells. In several species, they are aligned along the spinal cord, while in others they are clustered rostrally in the first part of the spinal cord. Several hypotheses have been advanced for the function of this neuron system. For many years, these neurons were considered persistent
Rohon-Beard cells. That hypothesis has been excluded because the supramedullary neuron differentiation begins at advanced stages of development and is completed in juveniles, and because these neurons are present in juveniles and adults of Hyppocampus and Syngnathus, species lacking RohonBeard cells during development (Marini and Benedetti, 1992).

On the grounds of electrophysiological research, Bennett et al. (1959 a,b,c) put forward the idea that supramedullary cells are motoneurons of the autonomic nervous system, even though their axons emerge from the spinal cord through the dorsal roots. Recent neuroanatomical studies in Takifugu niphobles demonstrate that the processes of the clustered supramedullary cells project peripherally through the trigeminal, vagal and spinal nerves (Funakoshi et al., 1995).

Our previous immunohistochemical research on the detection of neuropeptides show that aligned supramedullary neurons exhibit positive immunoreactivity to CCK-8, CCK-39 and gastrin (18-34), both in Perciformes (Coris julis) (Benedetti and Mola, 1988) and in Scorpaeniformes (Trigla lucer$n a$ and Scorpaena porcus) (Benedetti et al., 1993). Funakoshi et al. (1998) confirm gastrin/CCKimmunoreactivity in T. niphobles clustered supramedullary neurons. The same immunopositivity is 
also found in nerve terminals surrounding the cutaneous mucous glands, as well as in some free nerve endings in the epidermal layer near the mucous glands. The authors suggest a role as main autonomic elements of a sensory-motor reflex system for these neurons.

With the aim of clarifying if the supramedullary cells are components of the autonomic nervous system, we undertook the detection of catecholamines in the aligned supramedullary neurons of Coris julis (L.). We have chosen this species as a very suitable material for our neurobiological studies (Benedetti and Mola, 1988; Mola et al., 1992; Mola and Barozzi, 1998) because C. julis offers many advantages, among which are its availability all year round and the ease with which it can be kept in an aquarium. In this species, there are about one hundred supramedullary cells (cell diameter 60-65 $\mu \mathrm{m})$ of different shapes and scattered below the external limiting membrane for about the first half (i. e. ca. $3 \mathrm{~cm}$ ) of the spinal cord (Fig. 1).

\section{MATERIALS AND METHODS}

We examined twenty specimens $(9-18 \mathrm{~cm}$ in length) of Coris julis (L.) captured in the Tirrenian Sea (Italy) and reared for seven days in oxygenated sea water tanks.

For monoamine detection, in ten of these animals axonal transport was blocked by the intraperitoneal injection of colchicine (Sigma, USA), 50 $\mu \mathrm{g} / \mathrm{g}$ body weight in isotonic saline solution
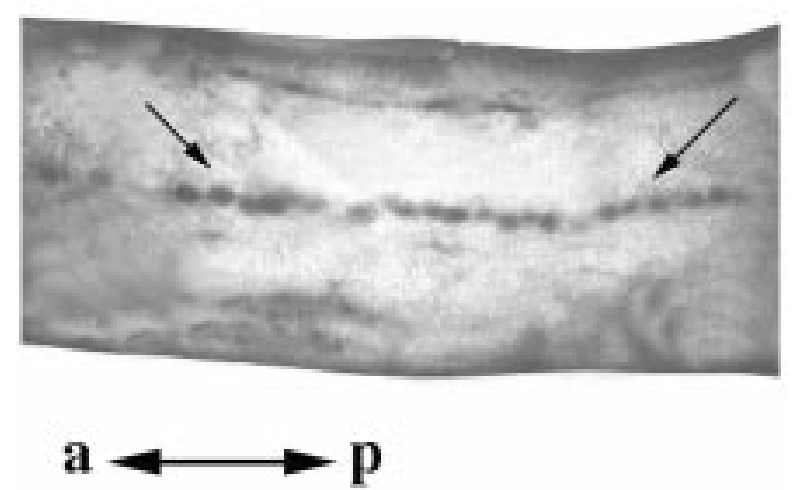

Fig. 1 - Picture at the stereomicroscope of a Coris julis spinal cord segment (ca. $1 \mathrm{~cm}$ long), in toto. Arrows indicate the supramedullary cells lying on the dorsal surface (frontal view). a $\mathrm{p}=$ antero-posterior axis. Staining with Trypan blue. (340mosm), $24 \mathrm{~h}$ before the dissection (Batten et al., 1990). The other ten animals were used for enzyme detection.

All twenty animals were sacrificed by decapitation; their spinal cord was rapidly removed and fixed in $4 \%$ freshly depolymerized paraformaldehyde in $0.1 \mathrm{M}$ phosphate buffer saline (PBS), $\mathrm{pH}$ 7.4 , for $24 \mathrm{~h}$ at $4^{\circ} \mathrm{C}$. Thereafter, the material was cryoprotected for $24-48 \mathrm{~h}$ in PBS containing $20 \%$ sucrose at $4{ }^{\circ} \mathrm{C}$. Fixed tissues were embedded in O.C.T. compound (BDH, UK), frozen and cut in a cryocut (Micron). Transversal sections (16 $\mu \mathrm{m})$ were picked up on gelatin-coated glass slides.

After inhibition of endogenous peroxidases by incubation for $30 \mathrm{~min}$ in $100 \%$ methanol containing $0.3 \% \mathrm{H}_{2} \mathrm{O}_{2}$, sections were incubated overnight at $4{ }^{\circ} \mathrm{C}$ in a moist chamber with primary antisera. We tested the following polyclonal antibodies: anti-tyrosine hydroxylase (TH) (Sigma, from mouse, 1:750 titer); anti-dopamine $\beta$-hydroxylase $(\mathrm{D} \beta \mathrm{H})($ Chemicon, USA, from rabbit, 1:400 titer); anti-dopamine (DA) (Instar, USA, from rabbit, 1:2500 titer) and anti-noradrenaline (NA) (Chemicon, from rabbit, 1:250 titer). All antisera were

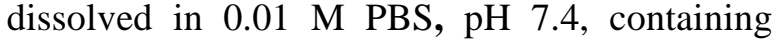
$0.3 \%$ Triton $\mathrm{X}-100$. The antigen-antibody complexes were visualized using biotinylated goat anti-rabbit or goat anti-mouse secondary serum (Dako, Italy) (diluted 1: 250 in $0.01 \mathrm{M}$ PBS pH 7.4 , containing $0.3 \%$ Triton $\mathrm{X}-100$ ) for $30 \mathrm{~min}$ at room temperature, followed by the Biotin-Avidin Complex/HRP (Vectastain ABC system, Vector Labs., USA) in TRIS, pH 7.6, for $45 \mathrm{~min}$ at room temperature. 3,3'Diaminobenzidine tetrahydrochloride (DAB, Sigma) was employed as a chromogen.

Only for monoamine detection, before immunohistochemical reactions, the slides were incubated in a reducing solution containing $0.05 \mathrm{M}$ sodium hydroborate for $3 \mathrm{~min}$ and rinsed 6 times for $5 \mathrm{~min}$ at $4^{\circ} \mathrm{C}$ in $0.01 \mathrm{M}$ PBS, pH 7.4, containing $0.85 \%$ sodium metabisulphite. Sodium metabisulphite at the same concentration was added to the normal serum (incubation for 60-90 $\mathrm{min}$ ) and to the serum containing antibodies.

The specificity of immunostainings was always checked by incubating sections with normal serum instead of specific antisera or incubating sections with antiserum preabsorbed with the respective antigen $(10-100 \mu \mathrm{g} / \mathrm{ml})$. The preabsorbtion procedures were carried out overnight at $4^{\circ} \mathrm{C}$. 
The slides were mounted with Eukitt and examined under a Leitz Diaplan microscope equipped with WILD photoautomat MPS 45. Some photos were made with Nomarski interference.

\section{RESULTS}

The present immunohistochemical study, aimed at identifying classical neurotransmitters in the supramedullary neurons of $C$. julis, pointed out immunopositivity to antibodies against some enzymes and reaction products involved in the biosynthesis of catecholamines. Indeed, cytoplasmic immunopositivity was found in all supramedullary

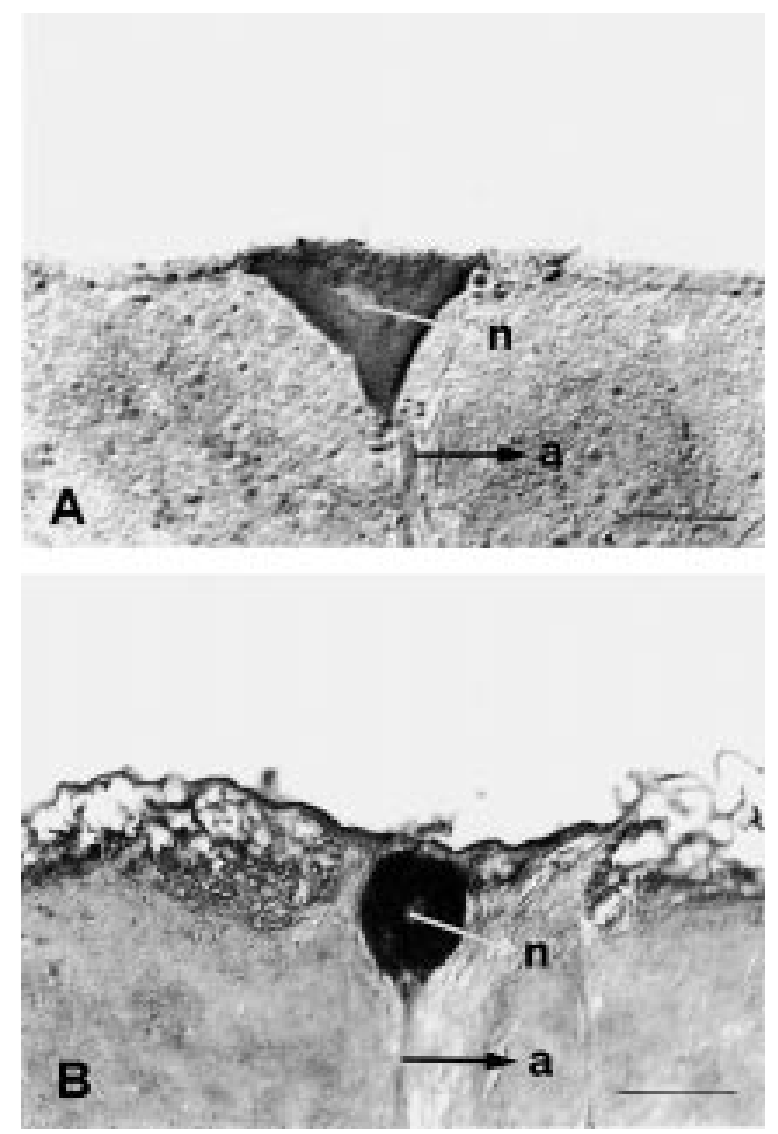

Fig. 2 - A) Transversal section of Coris julis spinal cord showing a supramedullary neuron (s. n.) immunoreactive to TH (1:750 dilution). Photo with Nomarski interference. $\mathrm{n}=$ nucleus, $\mathrm{a}=$ axon. Scale bar $=50 \mu \mathrm{m}$. B) Transversal section of $C$. julis spinal cord showing another supramedullary neuron immunoreactive to NA (1:250 dilution) after colchicine treatment. $\mathrm{n}=$ nucleus, $\mathrm{a}=$ axon. Scale bar $=50 \mu \mathrm{m}$. neurons with anti-TH antibodies (Fig. 2A), anti$\mathrm{D} \beta \mathrm{H}$ antibodies and anti-NA antibodies (Fig. 2B). Immunoreactivity to anti-NA was almost of the same intensity in all supramedullary cells, probably due to axonal transport blockade, which, as is known, prevents neurotransmitter transit from the neural soma. The morphological pattern showed neurons with a process running ventrally (Fig. 2A, 2B), the course of which was not easily detectable. No immunoreactivity was observed for anti-DA antibodies.

The control procedures resulted in the absence of reactions.

\section{DISCUSSION}

As is known, several molecules are produced during biosynthesis of catecholamines (L-DOPA, DA, NA and adrenaline); some of them may be the final neurotransmitter, or represent an intermediate reaction product in the synthesis of other functional catecholamines. Thus, to identify which of these substances plays the role of neurotransmitter, it is important to precisely establish where the biosynthesis process is interrupted by testing the presence or absence of the required enzyme. Positivity toward anti-TH and anti-D $\beta \mathrm{H}$ antibodies indicates an enzymatic activity linked to catecholamine synthesis. In particular, the presence of $\mathrm{D} \beta \mathrm{H}$ suggests that supramedullary neurons are not dopaminergic but rather noradrenergic or adrenergic; this is confirmed by the lack of immunoreactivity towards anti-DA antibodies and by the marked positivity to anti-NA antibodies. The lack of immunoreactivity towards anti-DA antibodies can be explained by supposing a rapid conversion of DA to NA by the enzyme D $\beta \mathrm{H}$; thus, DA is present in amounts too small to be detected by usual immunohistochemical methods. Immunopositivity towards anti-NA antibodies, detectable in all supramedullary neurons, suggests that in these cells NA does not represent an intermediate step in the synthesis of adrenaline, but plays a role in neurotransmission.

The supramedullary neurons of $T$. niphobles turn out not to be immunoreactive for ChAT or TH (Funakoshi et al., 1998). The authors state that these cells constitute a class of non-adrenergic/noncholinergic autonomic neurons, which project 
peripheral processes to both the cutaneous mucous glands and epidermis. On the contrary, our results showed immunoreactivity not only for TH but also for $\mathrm{D} \beta \mathrm{H}$ and $\mathrm{NA}$. The different immunoreactivity found for the first enzyme of catecholamines biosynthesis may be due to different specificities of tested antibodies or to other methodological differences. It is improbable that species differences can account for the diversity in immunoreactivities to TH between $C$. julis and T. niphobles. Indeed, in all species that have been studied by different authors, the supramedullary cells, both aligned and clustered, share the same main morphological (Marini and Benedetti, 1992; Cuoghi and Marini, 2001) and immunohistochemical (Benedetti and Mola, 1988; Benedetti et al., 1993; Funakoshi et al., 1998) characteristics. Moreover, immunopositivity to anti-NA was also found in the clustered supramedullary neurons of the pufferfish Tetraodon fluviatilis (Cuoghi, unpublished data). For these reasons, we think that supramedullary neurons of fish constitute a noradrenergic system.

In addition, considering that cutaneous mucous glands in amphibians are innervated by the sympathetic adrenergic nerves, the hypothesis on the autonomic nature of supramedullary neurons (Bennett et al., 1959 a,b,c; Funakoshi et al., 1998) appears strengthened by the present data.

Our previous immunocytochemical studies have shown that all supramedullary neurons of $C$. julis are immunoreactive towards a gastrin/CCK-like peptide (Benedetti and Mola, 1988). This seems to be the first known case of co-localization of a neuropeptide and monoamine in the nervous system of teleosts. At the moment, we can speculate that the neuropeptide acts in this noradrenergic neuronal system as a neuromodulator. Some support for this hypothesis comes from mammalian neuronal systems that use CCK in order to modulate monoamine action. For example, it is known that systemic administration of CCK releases noradrenaline in the dorsal region of the rat supraoptic nucleus (Kendrick et al., 1991; Onaka et al., 1995).

\section{REFERENCES}

Batten T.F., Cambre M.L., Moons L., and Vandesande F.: Comparative distribution of neuropeptide-immunoreactive systems in the brain of the green molly, Poecilia latipinna. J. Comp. Neurol. 302, 893-919, 1990.
Benedetti I., and Mola L.: Survey of neuropeptide-like immunoreactivity in supramedullary neurons of Coris julis (L.). Brain Res. 449, 373-376, 1988.

Benedetti I., Mola L., Marini M., and Calzolari C.: Neuroanatomical and immunohistochemical studies on the dorsal neurons in the spinal cord of Trigla lucerna L. and Scorpaena porcus L. (Scorpeniformes). Ann. Anat. 175, 77-80, 1993.

Bennett M.L.V., Crain S.M., and Grundfest H.: Electrophysiology of supramedullary neurons in Sphaeroides maculatus. I. Orthodromic and antidromic responses. J. Gen. Physiol. 43, 159-188, 1959a.

Bennett M.L.V., Crain S.M., and Grundfest H.: Electrophysiology of supramedullary neurons in Sphaeroides maculatus. II. Properties of the electrically excitable membrane. J. Gen. Physiol. 43, 189-219, 1959b.

Bennett M.L.V., Crain S.M., and Grundfest H.: Electrophysiology of supramedullary neurons in Sphaeroides maculatus. III. Organization of the supramedullary neurons. J. Gen. Physiol. 43, 221-250, 1959c.

Cuoghi B., and Marini M.: Ultrastructural and cytochemical features of the supramedullary neurons of the pufferfish Diodon holacanthus (L.) (Osteichthyes). Tiss. Cell 33, 491499, 2001.

Funakoshi K., Toshio A., and Reiji K.: Trigeminal, vagal and spinal projections of supramedullary cells in the pufferfish Takifugu niphobles. J. Comp. Neurol. 358, 552-562, 1995.

Funakoshi K., Kadota T., Atobe Y., Nakano M., Goris R.C., and Kishida R.: Gastrin/CCK-ergic innervation of cutaneous mucous glands by the supramedullary cells of the pufferfish Takifugu niphobles. Neurosci. Lett. 258, 171-174, 1998.

Kendrick K., Leng G., and Higuchi T.: Noradrenaline, dopamine and serotonin release in the paraventricular and supraoptic nuclei of the rat in response to intravenous cholecystokinin injections. J. Neuroendocrinol. 3, 139-144, 1991.

Marini M., and Benedetti I.: The Rohon-Beard cells and supramedullary neurons in Teleosts. In: Neurology Today. Selected Symposia and Monographs U.Z.I., vol. 7, (Eds. Benedetti, I., Bertolini, B., and Capanna, E.), Mucchi, Modena, 1992, pp. 217-236.

Mola L., and Barozzi G.: Effects of prolonged aquarium life on the supramedullary neurons of Coris julis (Labridae). Anim. Biol. 7, 59-65, 1998.

Mola L., Marini M., and Benedetti I.: Acid phosphatase in the supramedullary neurons of Coris julis (L.). Eur. J. Histochem. 36, 233-236, 1992.

Onaka T., Luckman S.M., Guevara-Guzman R., Ueta Y., Kendrick K., and Leng G.: Presynaptic actions of morphine: blockade of cholecystokinin-induced noradrenaline release in the rat supraoptic nucleus. J. Physiol. 482, 69-79, 1995. 